\title{
Saúde Custodiada: Representações dos Guardas Sobre o Hospital de Custódia
}

Health in custody:

Guards' representations on the custodial hospital
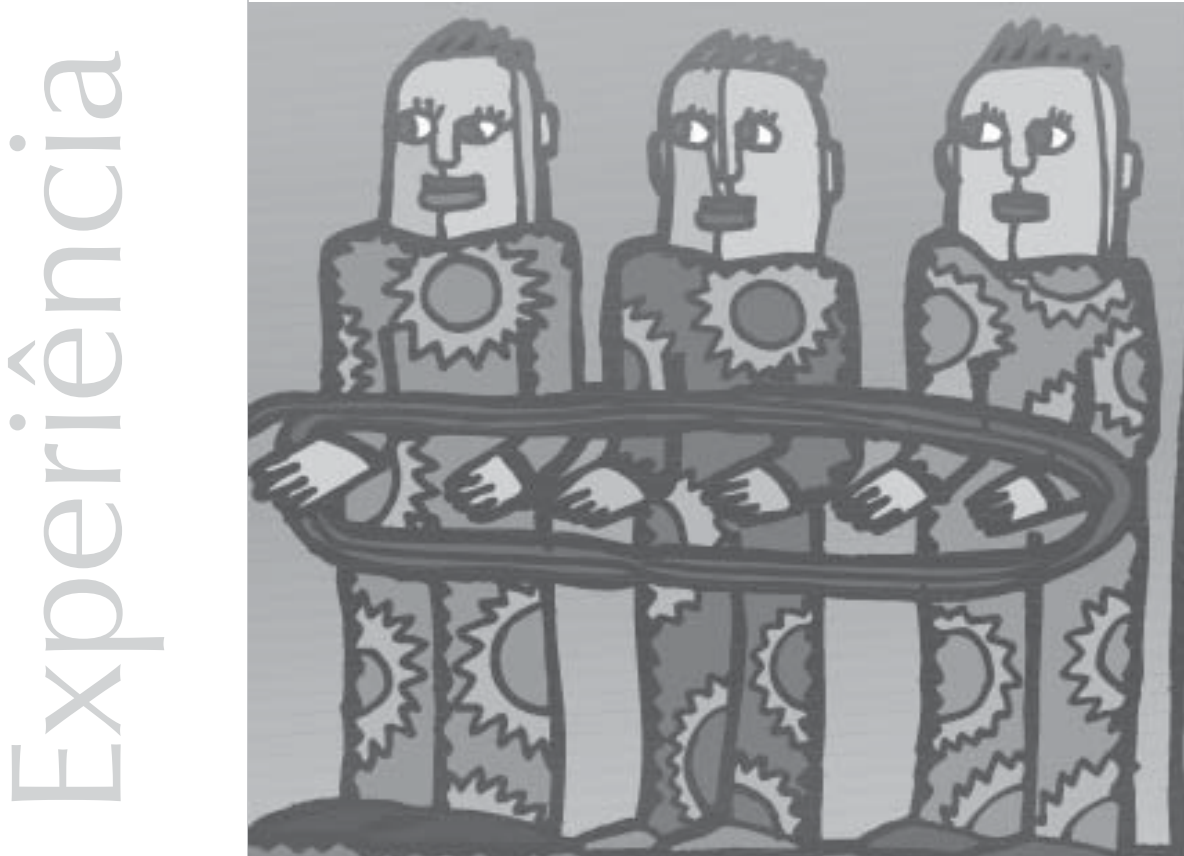

Agradecimentos às instituiçōes e profissionais que colaboraram com a pesquisa, especialmente a Signe Eldøy, Tove E. Belland, Trine D. Daatland, Aase Alstad $e$ Vivian Nilsen. 
Resumo: Este trabalho trata das representações sociais dos guardas do Hospital de Custódia e Tratamento Psiquiátrico a respeito do tratamento da saúde mental dos internos, haja vista a demanda por práticas e por uma política que atenda aos propósitos da reforma psiquiátrica e da legislação penal brasileira. Realizamos entrevistas semi-estruturadas com dez sujeitos, abordando o que pensam acerca do Hospital, do interno/paciente, do seu papel e da saúde na instituição. Analisamos os dados à luz da teoria das representações sociais e os distribuímos em categorias segundo a análise temática. Como resultado da investigação, verificamos que, embora grande parte dos entrevistados mantenha visões e crenças sobre uma loucura perigosa e apontem a manutenção do seu papel como meio de controle, revelam discursos e práticas mais sensíveis à condição do louco infrator. Vislumbraram pouca mudança com a entrada dos técnicos, porém entendem como importante o aprimoramento das ações de saúde.

Palavras-chave: loucura, saúde mental, guardas prisionais, representações sociais.

Abstract: This paper discusses the social representations of the prisoners' guards who work at the Hospital de Custódia e Tratamento Psiquiátrico about the intern's mental health treatment in order to analyze the demands of practices and a health policy that takes into account the psychiatric reform goals and the Brazilian criminal law purposes. Ten guards were interviewed and questioned about the Hospital, the interns/patients, their roles at the institution and mental health in the institution. Their lines were analyzed based on the social representation theory and categorized according to the themathical analysis. As a result, we found that, despite of the maintenance of visions and beliefs in a dangerous madness and in its control, most of the interviewed produced discourses and practices more sensitive to the interns' condition. Moreover, in their view, health professionals didn't bring many changes to the Hospital, otherwise they think the improvement of actions in that area is essential.

Key words: madness, mental health, prisoners' guards, social representations.

O Hospital de Custódia e Tratamento Psiquiátrico de Sergipe, até pouco tempo Manicômio Judiciário, como ainda é usualmente conhecido, é uma instituição vinculada à Secretaria de Estado da Justiça e Cidadania, destinada à custódia e ao tratamento de pessoas que, acometidas de algum tipo de transtorno mental, tenham praticado um crime em razão dessa condição. O paciente jurídico, como alguns, paradoxalmente, preferem denominar, são definidos pelo Código Penal Brasileiro, em seu art. 26, como inimputáveis ou semiimputáveis, ou seja, "incapazes de entender o caráter ilícito da ação delituosa", e, por esse motivo, in tese, não podem ser condenados em decorrência da sua irresponsabilidade penal, ficando, portanto, sob "medida de segurança" até que seja verificada a cessação da periculosidade.
Embora previsto na Lei de Execuções Penais, o "tratamento" praticamente inexistia, e, a despeito da presença da psiquiatria, da enfermagem e do serviço social, era possível afirmar que o Hospital de Custódia e Tratamento Psiquiátrico (HCTP) em Sergipe tinha, como objetivo, apenas a mera segregação daquela que é considerada, social e juridicamente, a classe de loucos mais perigosa, pois, além de loucos, são enquadrados como criminosos. É uma categoria criminosa que atemoriza por estar supostamente baseada em razões infundadas e difíceis de serem explicadas, descritas e previstas, cabendo, então, às ciências psicológica e médica, a árdua tarefa.

A propósito da escancarada política de exclusão, que, muito longe de incomodar a sociedade, a tranqüiliza, temos que o 
As vozes que, em tempos remotos, já clamavam por um tratamento mais humanizado ao doente mental, iniciadas na ltália a partir das mudanças

implementadas no atendimento por Basaglia e

seguidores (Rotelli; De Leonardis; Mauri, 1990), também retratadas por Goffman (2001), Foucault (2000a; 2000b; 2001)e tantos outros, que se tornaram

clássicos e leituras obrigatórias, ecoarame

fizeram surgir novas vozes que vêm contribuindo para que as políticas de saúde mental sejam

continuamente postas em xeque e reformuladas.

1 DANTAS, M. A. F. Interfaces entre saúde $e$ justiça: expectativas de reorientação da política de atenção ao louco infrator no Manicômio Judiciário de sergipe. 2003. Mo n o g r a $f i$ a (Especialização em psicologia social) Universidade Estadual de Santa Cruz, Ilhéus/BA. movimento de luta em prol da reforma psiquiátrica no Brasil e no mundo contribuiu para alarmar e denunciar as irregularidades e os abusos cometidos no âmbito dos hospitais e asilos, onde ainda são, diariamente, constatadas práticas discriminatórias e maustratos, que não só marginalizam como degradam a pessoa portadora de transtorno mental.

As vozes que, em tempos remotos, já clamavam por um tratamento mais humanizado ao doente mental, iniciadas na Itália a partir das mudanças implementadas no atendimento por Basaglia e seguidores (Rotelli; De Leonardis; Mauri, 1990), também retratadas por Goffman (2001), Foucault (2000a; 2000b; 2001) e tantos outros, que se tornaram clássicos e leituras obrigatórias, ecoaram e fizeram surgir novas vozes que vêm contribuindo para que as políticas de saúde mental sejam continuamente postas em xeque e reformuladas. Hoje falamos em desinstitucionalização do doente mental, e não na sua simples desospitalização ou desinternação, haja vista o fato de se pensar a saúde como um processo que envolve fatores não mais reduzidos à visão hegemônica de cunho biologizante, organicista e individualizante, que alguns teimam em manter, e sim, como produto de condições sociais, culturais e econômicas favoráveis.

No Brasil, a progressiva constituição de uma rede de assistência extra-hospitalar, através dos centros de atenção psicossocial (CAPS), hospitais-dia, residências terapêuticas, pautadas nos princípios erigidos pelo Sistema Único de Saúde (SUS), emergiram em todo o País como resultado desse avanço no processo de desconstrução do estigma que cerca o doente mental e a sua relação com a sociedade.

É interessante mencionar a inclusão dos HCTPs, que permaneceram, por longo período, na obscuridade, nas metas de programas e projetos promovidos pelas instâncias governamentais da área da saúde. Isso valida a nossa crença na distribuição da competência por várias áreas da política governamental, devendo-se falar em "competências". Entretanto, regida por uma legislação penal extremamente distante da realidade do HCTP, é a Justiça estadual que detém o monopólio da gestão.

A Secretaria da Saúde do Estado de Sergipe (SES) ampliou o seu quadro de servidores, nomeando, de forma inédita, profissionais de áreas diversas, mediante concurso público. Profissionais oriundos da saúde mental foram lotados no então Manicômio Judiciário com a missão de implantar e implementar a política de atenção ao louco infrator naquela instituição. Sem quase nenhum tipo de respaldo políticoinstitucional de ambas as secretarias, os profissionais de níveis médio e superior psicóloga, terapeuta ocupacional, enfermeira, técnicos e auxiliares de enfermagem adentraram o Manicômio Judiciário e enfrentaram as mais diversas "resistências".

A princípio, contavam com um instrumento legal, a Portaria no 632/02, do Ministério da Saúde, a qual firmava um pacto entre os Ministérios da Saúde e Justiça e visava à operacionalização de um plano operativo de saúde nos presídios, o que incluía o HCTP. O referido plano deveria ser pensado pelas respectivas instâncias estaduais, havendo, de outro lado, uma contrapartida dos Ministérios, em termos de financiamento dos custos de materiais físico-estruturais e recursos humanos. Em pesquisa anterior ${ }^{1}$, vislumbramos o processo de inserção dos profissionais da saúde e as suas expectativas em torno da reorientação do modelo de atenção ao louco infrator no Manicômio Judiciário de Sergipe, tendo constatado que, não obstante as dificuldades inicialmente verificadas no que tangem às demandas de toda sorte - reservas dos agentes penitenciários e da administração do Hospital, boicotes, precariedades do prédio, não fornecimento de materiais necessários à realização de atividades 
terapêuticas, parco apoio das Secretarias, incompatibilidades entre os próprios técnicos e onipotência das decisões judiciais -, criouse uma perspectiva de reversibilidade da situação daquelas pessoas condenadas à "prisão perpétua", a partir da "invasão" da saúde e da construção de um espaço sequer imaginado, em que foi possível colocar em pauta as inúmeras violências vivenciadas no interior do manicômio.

Considerando que, desde a entrada de profissionais de saúde mental no HCTP, algumas mudanças estão sendo realmente implementadas, implicando uma reformulação dos modelos existentes, e, supondo que tais transformações requeiram novas formas de pensar e fazer dos seus atores, como os guardas prisionais, que são a categoria profissional de maior expressividade em termos numéricos $\mathrm{e}$ têm uma função definida a priori, estes representariam socialmente a saúde e o seu papel em uma instituição de caráter segregacionista?

O nosso interesse em pesquisar a apropriação de novos conhecimentos pelo grupo de guardas prisionais, que compõem o quadro de funcionários do Hospital de Custódia e Tratamento Psiquiátrico de Sergipe, acerca da introdução de novos preceitos, práticas e valores pautados na perspectiva das políticas de saúde mental, pensados naquela instituição, ainda de forma incipiente, adveio da necessidade de acompanhar a inserção dos profissionais de saúde, então responsáveis pela inclusão do antigo Manicômio Judiciário, no rol das mudanças propostas pelo Movimento da Reforma Psiquiátrica no Estado.

Seguidas as análises sobre esse processo de iniciação ${ }^{2}$ dos profissionais de saúde mental em uma instituição marcadamente prisional e institucionalizante para todos os seus atores, no sentido de resguardar pouco ou quase nenhum espaço de promoção de medidas que possibilitassem aos internos/pacientes a sua "reinserção social", tanto em termos de visibilidade do HCTP junto à comunidade, aos familiares, às autoridades do Estado, aos promotores de justiça e, notadamente, ao Juiz da Vara de Execuções Penais, quanto em termos de mobilização e engajamento de outros 4serviços e redes de apoio funcionando como referência, foi-nos dada a oportunidade de comprovar que a abertura do antigo Manicômio Judiciário não ocorreu somente a partir da modificação do seu nome, conforme já previsto na Lei de Execuções Penais, mas, principalmente, com a disseminação de novas idéias, práticas, crenças e valores.

Em virtude desse processo de ressignificação do Hospital de Custódia e Tratamento Psiquiátrico, muito embora sérias dificuldades de ordem política, institucional e afetiva tenham contribuído continuamente para a instabilidade do "corpus operandi" , tal como mencionado anteriormente, cumpre-nos relatar, neste artigo, de que modo os guardas prisionais têm percebido as ditas "mudanças", como vêm se apropriando dos novos conceitos, bastante diversos de seu universo sociorepresentacional sobre o que seja um manicômio judiciário ou um HCTP, e de que forma o saber-fazer elaborado por esse grupo, bem peculiar, tem orientado as suas ações e o seu pensar em uma instituição reconhecidamente ambígua, em razão de seu caráter segregador e curativo.

Por esse motivo, entendemos ser fundamental compreender o funcionamento desse processo de aquisição, elaboração e compartilhamento de saberes em saúde mental pelos guardas prisionais e sua aplicação à nova realidade do HCTP, face à atual necessidade de reorientação e/ou adequação de suas práticas e seu papel, em meio à transição pela qual vem passando a instituição. Desse modo, à luz da teoria das representações sociais, buscamos desvelar quais são as representações sociais dos guardas prisionais acerca da saúde mental dos internos no Hospital de Custódia e Tratamento Psiquiátrico em Sergipe, a fim de entender a (re)definição de suas práticas, e, portanto, tecer uma análise a respeito dos avanços institucionais na respectiva área.
2 A pesquisa mencionada ocorreu no ano de 2003 , logo após o ingresso de recém-concursados da Secretaria de Estado da Saúde, nos meses finais de 2002.

3 Expressão aqui cunhada para designar a equipe de saúde mental, cuja atuação é, a nosso ver, impar na tomada de decisóes que envolvem todo o aparato institucional. 


\section{Revisão da literatura}

A criação do Manicômio Judiciário procedeu de amplos debates no campo jurídico-penal sobre a loucura criminosa, nos quais estavam também incluídos os presos que enlouqueciam nas prisões, período coincidente com a emergência da psiquiatria enquanto saber médico especializado.

Impulsionados pelos avanços da ciência alienista, no que se refere ao aprimoramento dos sistemas taxionômicos, os tribunais apostaram na construção de locais reservados ao tratamento do louco infrator e seu conseqüente isolamento social, fato esse que minimizaria os "prováveis riscos" afetos à população (Dantas, 2003).

Passaríamos da era dos suplícios, em que se punia e castigava na mesma medida, à época em que se corrigia, tratava e disciplinava, por meio de altos esquemas de vigilância e classificação dos corpos (Foucault, 2001).

Desde o Direito Penal clássico, a pena deixou de ser proporcional ao crime, e passou a ser aplicada em função das "disposições e tendências" do indivíduo, comungando, assim, com os ideais do movimento liberal que pregava a autodeterminação e o livrearbítrio. Entretanto, a loucura criminosa derrubou parte desses pressupostos, no instante em que passou a versar sobre "incapacidades intelectuais e volitivas" presentes em atos criminosos, um dos motivos que levou a psiquiatria a inserir-se no campo penal através dos laudos periciais (Peres e Nery Filho, 2002). O cabedal de recursos teóricos e instrumentos médicos, com fins comprobatórios, teve como principal objetivo definir a responsabilidade ou irresponsabilidade penal dos infratores da lei.

O caso em apreço

$d i s$ c u t $i$ d o

exaustivamente no livro

"Eu, Pierre Rivière, que

degolei minha mãe,

minha irmã e meu

irmão", organizado por

Michel Foucault (2000a).
Contudo, houve um momento na História em que os juízes permaneceram perturbados diante de um caso de parricídio, ocorrido no século XIX, na França, quando o autor do delito deu mostras de uma "loucura raciocinante" que contrariava todos os argumentos médicos até então apresentados, e ainda pairavam dúvidas entre os juristas quanto à penalização do sujeito (Foucault, 2000) ${ }^{4}$. Mais uma vez, entra em cena o saber psiquiátrico, em busca da legitimação, tecendo conceituações refinadas acerca do diagnóstico do doente mental e descrições elaboradas sobre a presença de sinais que explicassem e justificassem os seus comportamentos e a sua vida pregressa.

A monomania, por exemplo, foi um conceito de extrema relevância, cujo sentido designava uma loucura sem delírio, a qual, segundo Maciel (1999), contribuiu, de forma decisiva, para que os alienistas atingissem o ápice e passassem à reformulação da loucura, vista apenas em termos de transgressão da razão e da moralidade, atribuindo-lhe, então, o caráter de doença, passível de tratamento e explicação.

A partir daí, outras idéias surgiram, tais como a teoria da degeneração, de autoria de Morel, em 1857, que dispunha sobre a hipótese de haver uma carga hereditária mórbida, aliada a ambientes e raças desfavoráveis, como propulsoras da loucura, e, no campo da Antropologia criminal, a construção teórica de Césare Lombroso a respeito do criminoso nato, que fazia novamente alusão às predisposições ao crime, as quais poderiam ser identificadas com base em marcas e sinais visíveis de ordem anatomo-patológicas (Maciel, 1999).

A noção de periculosidade, assinalada como a probabilidade que o sujeito tem de delinqüir, é chave para compreender toda a trama de relações que envolvem o louco infrator e a sua inexpressividade social, enquanto cidadão de direitos. Inicialmente, o conceito foi cunhado a fim de justificar as medidas de segregação e ordenação dos espaços, conforme categorias: louco, criminoso, vadio, pobre, etc. Antes as ditas classes estavam

amontoadas em um mesmo espaço, 
geralmente encontradas nos porões das Santas Casas de Misericórdia ou nas prisões (Ribeiro, 1999).

O movimento eugenista trouxe uma contribuição para a disseminação de ideais que seguiam os ritos de "valoração de uma raça superior", no combate à miscigenação, que eram, todavia, baseados em princípios científicos que primavam pela manipulação genética e que influenciavam, de certa forma, o domínio das ciências que cuidavam da loucura (Ribeiro, 1999; Maciel, 1999).

No Brasil, a condição jurídica do doente mental só foi normatizada com a promulgação do primeiro Código Penal da República, em 1890, que determinava o Hospício Nacional de Alienados, no Rio de Janeiro, como local privilegiado de tratamento. Essa situação somente veio a ser regulamentada após sérias reivindicações por parte dos médicos em estabelecer espaços delimitados para tratamento, recuperação e cura dos doentes (Peres, 1997). Anteriormente, como já mencionado, toda a população marginalizada era relegada às casas religiosas e cárceres, como forma de coibir a livre circulação dos improdutivos e perigosos.

No entanto, a legislação sobre os manicômios criminais teve a primeira aparição com o Decreto $\mathrm{n}$ - 1.132, de 1903, elaborado pelo antigo diretor do Hospício de Alienados, o Deputado Teixeira Brandão, o qual chamava a atenção para a necessidade de estruturação física daquelas instituições e determinava a reserva de locais específicos ao louco criminoso em hospitais públicos, quando da não existência dos centros especializados (Maciel, 1999).

Em seguida, verificaram-se inúmeros problemas em relação a fugas e internações compulsórias sem mínimos critérios médicos, freqüentemente realizadas em razão de ordem judicial, e superlotação, o que suscitou a abertura do primeiro manicômio judiciário, cuja direção ficou a cargo do psiquiatra Heitor
Pereira Carrilho, no Estado do Rio de Janeiro, em 1921 (Carrara, 1998; Maciel, 1999).

Não obstante as denúncias e os óbices encontrados, o modelo iniciado no Rio de Janeiro motivou a criação de outros novos manicômios, que hoje estão espalhados por todo o País. Contudo, as mudanças de paradigmas em saúde mental atualmente ditam a extinção progressiva dos hospitais psiquiátricos e manicômios e a substituição desses modelos asilares por outros mais inclusivos, priorizando o atendimento ao portador de transtorno mental em unidades ambulatoriais, hospitais-dia e centros de atenção psicossocial.

Uma das maiores dificuldades enfrentadas nessa área são as relações conflituosas entre a Justiça e a saúde, constatadas nos procedimentos arbitrários dos juízes de Direito, principalmente quando da aplicação da medida de segurança.

A medida de segurança não é prevista no Código Penal brasileiro como uma modalidade de sanção e sim, como um meio de defesa social, cujo objetivo principal seria promover o tratamento dos inimputáveis ou semiimputáveis, ou seja, pessoas incapazes de entender o caráter ilícito do fato ao tempo da ação ou da omissão. Por essa razão, o louco infrator poderá ser remetido a um hospital de custódia e tratamento psiquiátrico, onde permanecerá "internado" por um período mínimo de três anos e condicionado à verificação da cessação de periculosidade, mediante exames psiquiátricos, ou será submetido a tratamento ambulatorial, a depender da gravidade e natureza do crime. Vale ressaltar que o tempo de permanência do "paciente" na instituição é quase infindo, a julgar pelos constantes indeferimentos dos juízes, os quais muito pouco levam em conta os pareceres médicos que opinam favoravelmente à desinternação. No entanto, devemos salientar a questão de muitos profissionais também negligenciarem o seu papel de orientadores e/
"O movimento eugenista trouxe uma contribuição para a disseminação de ideais que seguiam os ritos de "valoração de uma raça superior", no combate à miscigenação, que eram, todavia, baseados em princípios científicos que primavam pela manipulação genética e que influenciavam, de certa forma, o domínio das ciências que cuidavam da loucura."

Ribeiro e Maciel 
ou consultores das decisões judiciais, face à omissão veemente nos laudos acerca da questão.

Amarante e Torre (2001) afirmam que o objetivo da reforma psiquiátrica não se restringe a mudanças administrativas ou técnicas, sendo, sim, a superação do paradigma manicomial, cujo sucesso depende, essencialmente, da mudança nas formas de lidar com a loucura.

É nesse sentido que o movimento de reforma se preocupa também com o processo de reabilitação, definido na concepção de Kinoshita (1996) como a restituição do poder contratual do usuário, a ampliação da sua autonomia e o fomento de condições indispensáveis às trocas sociais. É fundamental que os profissionais representem o início dessa relação de contratualidade.

A reforma psiquiátrica e a desinstitucionalização estão imbricados como um só processo, refletindo novas possibilidades de atuação frente à loucura e propondo novos modos de a sociedade relacionar-se com ela. Muito embora pensemos um sujeito pleno e potencialmente capaz, sozinho ele não interfere no curso de sua história, e, por isso, ressaltamos a cooperação e o empreendimento por parte dos profissionais que, junto aos usuários, fazem o cotidiano das instituições.

\section{Referencial teórico- metodológico}

A teoria das representações sociais, fundada por Serge Moscovici ao final dos anos 50, na França, surgiu como uma tentativa de superar os consagrados modelos funcionalistas da ciência positiva, inovando ao tratar do conceito de representações enquanto saber compartilhado, originado no âmbito dos grupos, a partir não apenas dos processos cognitivos individuais, mas, sobretudo, em decorrência das atividades sociais que envolvem uma experiência comum de elaboração e adaptação de idéias estranhas ao universo cognoscente dos sujeitos em uma realidade consensual, dominada e com uma finalidade prática de orientação de condutas. É a isso que Moscovici e muitos de seus seguidores teóricos se referemao tornar o nãofamiliar em familiar.

A Psicologia social, na concepção de Moscovici (2001), tinha agora, como problema, compreender a transformação dos modos de pensamento e a criação de novos conteúdos a partir do grande advento dos meios de comunicação de massa e da difusão de teorias técnico-científicas entre as mais variadas comunidades. É, pois, mediante o compartilhar de saberes que as visões são moldadas e as realidades são constituídas.

Ao contrário do conceito de representações coletivas, proposto pelo sociólogo Émile Durkheim, as representações sociais, tal como foram formuladas por Moscovici, têm, como princípio, a indissociabilidade entre indivíduo e sociedade, deixando de lado o caráter autônomo, estável e homogêneo encontrado naquele conceito (Nóbrega, 2001).

Além das funções de formação das condutas e guia das comunicações sociais, já pensadas por Moscovici, Abric (2000), pesquisador de corrente mais estruturalista, pontua ainda duas outras funções: a identitária, que permite afirmar positivamente a imagem do grupo e suas especificidades, e a justificadora, na qual é possível agregar os valores que permitem a diferenciação de um dado grupo em relação aos demais.

O saber do senso comum, como são geralmente definidas as representações sociais, segundo Wagner (1998), surge em função de atender necessidades de ordem prática, que, muitas vezes, ocorrem em virtude de mudança nas condições sociais de vida de uma determinada população, motivo pelos quais os objetos sociais passam por uma reelaboração e modificação. Decorre, desse processo, que fenômenos desconhecidos ao grupo, emergentes em 
situação de mudanças, se relevantes, são postos em vias de comunicação coletiva, de modo a se tornarem inteligíveis e controlados.

É justamente nesse contexto de mudança, de inserção de novas vias de "comprometimento socioinstitucional", ou a sua mera expectativa, assim como de (re)formulação de novas identidades sociais, que, particularmente neste trabalho, buscaremos demonstrar como as representações sociais podem ser originadas em e a partir de condições sociais específicas.

Muito embora Wagner (1994) tenha assinalado que a maioria das pesquisas em representações sociais, analisadas em nível social, estejam relacionadas a movimentos de mudança e a situações de conflito pelos quais passam os grupos, acreditamos que, além de seguir essa "tendência", consideramos que as forças ideológicas, políticas e culturais insistem em manter intangíveis certas representações, a exemplo do nosso grupo de guardas prisionais. Vale assinalar que as representações genuinamente coletivas também dão conta das diferenças e divergências presentes nas relações inter e intragrupais. Wagner (1994) nos alerta sobre a existência de sub-representações presentes em grupos distintos de uma mesma instituição e explica, ainda, que as representações de um mesmo objeto social passam por estados de elaboração os mais variados, de acordo com a sua relevância.

\section{Método}

No Hospital de Custódia e Tratamento Psiquiátrico, estão lotados trinta e seis guardas prisionais plantonistas, distribuídos em quatro equipes, com seis homens e três mulheres em cada uma delas.

Realizamos entrevistas semidirigidas com dez guardas prisionais, todas devidamente gravadas no ambiente institucional, seguindo um roteiro através do qual intentamos alcançar os objetivos propostos inicialmente. Valemos-nos do entendimento dos sujeitos acerca do HCTP sobre a dinâmica institucional e sua função, do interno/paciente, das concepções sobre o desempenho da sua atividade funcional tal como foi concebida e nos moldes atuais, da entrada de profissionais de saúde e o trabalho por eles desenvolvido e, finalmente, das mudanças percebidas desde o ingresso do entrevistado no hospital.

Procedemos à análise dos dados através da técnica da análise temática, da análise do conteúdo, e passamos a dispor os resultados em categorias que foram discutidas e ilustradas com as falas dos entrevistados.

\section{Análise dos dados}

Ao procedermos à coleta de dados, foi surpreendente encontrar o Hospital de Custódia em nova fase, bem diferente da época em que investigamos as expectativas da equipe técnica, pois os profissionais de saúde estavam em processo de desligamento e transferência da instituição, retornando à secretaria de origem.

O HCTP conta, atualmente, com sessenta e quatro internos/pacientes, sendo que apenas três são mulheres; uma delas não apresenta problema mental, e foi transferida do presídio feminino. Trinta pessoas, do número total, têm medida de segurança, e as demais, não.

Em relação aos guardas prisionais, encontravamse "agitados" diante da redefinição do regime de plantão, sendo evidente a insatisfação com os novos horários, pois retornariam ao serviço em menor espaço de tempo.

Além disso, encontramos funcionários advindos de setores administrativos da Secretaria de Justiça, os quais estavam cumprindo o plantão mediante a expectativa de uma gratificação prevista em lei. Muitos dos entrevistados estavam voltando à atividade de guarda prisional, outros estavam ali pela primeira vez e haviam chegado recentemente, o que prejudicou a avaliação dos itens que versavam 
sobre as mudanças percebidas em relação à saúde mental dos internos no HCTP.

Algumas variáveis tiveram influência nas respostas e na construção do discurso, tendo em vista a presença de entrevistados estudantes universitários e já graduados da área de ciências humanas e das ciências jurídicas. É necessário ressaltar que tivemos dificuldades em entrevistar os guardas prisionais com mais tempo de casa, que se mostravam bastante resistentes, mas, sobretudo, os mais jovens e os estudantes de Direito, que alegaram não ter muito a dizer ou não saber discursar, no caso dos primeiros, e ter receio de falar "a mais do que deviam", no caso dos últimos.

Todavia, acreditamos que os dados foram significativos e alcançaram os nossos objetivos propostos a priori, não obstante as dificuldades iniciais relacionadas à participação dos entrevistados. Realizamos as entrevistas com duas equipes de plantão, cujos participantes eram de universo sociocultural bem diversificado, e, além dos plantonistas, entrevistamos uma guarda que trabalha no setor administrativo interno, mas já havia realizado trabalho de plantão no HCTP.

Os dados analisados foram categorizados em quatro grandes temas, que serão discutidos a seguir:

\section{A ambiguidade do modelo institucional}

Os guardas prisionais revelam, em suas falas, uma ambigüidade própria da constituição do Hospital de Custódia e Tratamento Psiquiátrico, tanto em termos de sua funcionalidade quanto em termos de estruturação física, recursos materiais e humanos disponíveis e indisponíveis. Os sujeitos, então, falam do HCTP, ou Manicômio Judiciário, como uma instituição cuja finalidade seria a de "tratar", "cuidar", mas fazem presente, em algumas linhas, que ela também foi concebida para "controlar", "corrigir", "punir" e "modificar": ...segregar pessoas que cometeram, infringiram o Código Penal e estão aqui pra cumprir essas penas...é tratar, entendeu?...pra que elas possam ingressar na sociedade de uma forma mais pacífica...enquanto eles estão aqui, eles permanecem controlados, entendeu?....aqui não, eles realmente vem aqui pra cumprir uma pena, de uma forma punitiva, mas pra se tratarem também aquele mal, né? O transtorno mental... E1

...mesmo que seja um hospital, mas eles estão aqui...eles vieram por ordem do juiz...eles praticaram crime. E7

...o Estado custodia o interno, o interno fica sem o poder, o Estado fica com o poder do interno...mas o Estado tem a obrigação de ressocializar, reeducar, não é isso? É de inseri-lo, reinseri-lo na sociedade...isso com os internos considerado os normais entre aspas...mas com esses aqui a LEP também tem uma função e não está cumprindo...eu acho que esse interno ele deveriam sim ter um acompanhamento...e aqui não tem. Eles deveriam ficar custodiados pelo Estado, porque, afinal de contas, eles cometeram um crime... E6

...seria de tentar reeducá-los, ressocializar pra voltar para a sociedade como pessoas normais. E3

...a gente tá trabalhando com pessoas...com tratamento psicológico, né?...é totalmente diferente... E5

Para os guardas prisionais, fica patente que os modelos são falhos; o HCTP cumpre as exigências do Estado, no sentido de custodiar, contudo, em relação ao atendimento das atividades corriqueiras e próprias de um hospital, isso não se verifica na prática:

...então eu acho que o Estado não está cumprindo com o seu dever...aqui está servindo apenas como um amontoado de corpos que já não estão mais servindo pra a sociedade...a sociedade repeliu, entendeu? E aqui é um amontoado de corpos, de corpos que já não servem mais... E6 
...não deveria nem existir...que é uma instituição falida, né?...não tem sentido jurídico, não tem sentido médico, não tem sentido terapêutico...terapêutico com grades?...como você vai pensar em algo terapêutico? Já quebra qualquer perspectiva de terapêutico, né? E10

É interessante observar que muitos dos entrevistados apontam uma insustentabilidade do HCTP, pois afirmam existir uma distância entre teoria e prática. Na teoria, há um propósito previsto em lei, no entanto, está longe de alcançar os seus objetivos e metas dadas as carências físico-estruturais e de assistência aos internos/pacientes e, principalmente, frente à expectativa social em torno do louco infrator e da sua reinserção.

...na teoria, era pra funcionar com toda a estrutura pra uma adequação do interno, pra eles voltarem melhor, só que, na prática, isso não acontece porque o governo não dá estrutura pra isso, entendeu?... E3

...o pessoal da Justiça somos nós, agentes, o pessoal da saúde é separado, são duas coisas totalmente afastadas...é tanto que é uma coisa que eu discordo, né? ...eu acho que, quando é hospital, é hospital, eles vão ao médico, o trabalho é do pessoal de saúde mas, como eles são considerados pessoas é, pessoas perigosas, isso aqui não teria condições de ser um hospital, teria de ser um manicômio judiciário...e teria assim o pessoal da saúde, pelo fato de que os internos são controlados através de remédios, mas não porque isso aqui teria condições de ser hospital...você já viu hospital prender alguém? E4

...que deveriam ser punidos de alguma forma, não apenas mantendo segregados, mas que, por que eles vão passar aqui, pode ter certeza, eles vão voltar em casa... E1

...falta muita coisa pra ser hospital, né? E9

O HCTP apresenta-se como o "lugar de castigo", lugar para o qual são encaminhados os guardas que, de alguma forma, contestaram as normas do sistema; entretanto, os atores dizem que a realidade no cotidiano do hospital é muito diferente das demais unidades prisionais, em razão de ser "tranqüilo", haver tempo para realizar outras atividades e não haver um grande contingente de internos:

eu vim porque briguei e me mandaram pra cá como castigo...eu fiquei dezessete dias aqui e foi o paraíso...aí eles achavam assim, que eu não tava me adaptando no COPECAM e mandaram pro lugar de louco...'vai ser um castigo pra ela'...mas, quando eu cheguei aqui, foi um paraíso. E6

...eu pedi pra vim pra cá...porque eu acho que o plantão aqui é mais tranqüilo e pra quem estuda, aqui é melhor. Esquenta menos a cabeça. E4

Inclusive aqueles entrevistados que buscam informações junto a outros colegas que passaram pela instituição, optam pela transferência, justamente em decorrência das "vantagens" que a rotina lhes traz.

...por incrível que pareça, quando eu vim pra cá, o pessoal dizia, 'ah, você vai para um lugar que não trabalha', lá não faz nada, ao contrário, aqui eu trabalho muito mais do que no COPECAM...aqui, eu entro no do pavilhão de manhã, de tarde, de noite... E2

...aqui é hospital, certo?...aqui é diferente...o ambiente em si já transmite paz...tem pouco interno, entendeu? E6

Outros ainda se apavoram diante do incerto, do imprevisível:

...hospital de doido... a gente fica meio receoso porque pensa, só tinha doido...mas, quando eu vi realmente não é bem assim. E2

...o pessoal comenta: hospital de doido, então a gente fica meio receoso, né? Mas depois de uma convivência, a gente vai se adaptando...tranqüilo. E5 ...eu pedi pra vim pra cá...porque eu acho que o plantão aqui é mais tranqüilo e pra quem estuda aqui é melhor. Esquenta menos a cabeça. E4 


\section{Afinal de contas, quem é o cliente?}

A visão que os guardas prisionais têm a respeito do sujeito de sua atenção ainda está muito atrelada ao interno e preso, que está sob regime de reclusão em função do crime praticado; no entanto, percebemos sutilmente que, apesar da íntima relação que mantêm com a crença em um sujeito que por eles deve ser custodiado, tem início a mudança em concebê-los como doentes que necessitam de tratamento:

...quando eles saírem, eles podem continuar e ser uma pessoa melhor, entendeu? E não cometer o erro que cometeram no passado... E3

...se os internos tivessem, é, tivessem condições de serem tratados como pacientes, como pacientes, e não como detentos. E4

...pessoas que têm algum problema com a Justiça, que não podem ficar numa carceragem comum... E2

... como eles são inimputáveis, ficam aqui não como presos, mas como internos...então o interno, pela natureza você já sabe que tem de lidar de forma diferente, entendeu? E são pessoas especiais... E6

...o tipo de interno que tem aqui é diferente...são pessoas em tratamento psiquiátrico, né? E8

...a princípio, seriam loucos criminosos ou criminosos loucos, ou..mas, se você considera criminoso um sujeito que, que em um determinado momento quebra um, um patrimônio, quebra um...quebra tudo em casa, a família não consegue dar conta, quer se livrar...são pessoas confinadas que estão excluídas da sociedade...só que ele é duplamente excluído...só em dizer que ele é doente, é a própria exclusão. E10
Entretanto, ainda vige a crença de que os pacientes são perigosos, imprevisíveis, e, muito embora estejam submetidos a um tratamento diferenciado no que tange ao suposto atendimento médico e psicossocial, são pessoas que cometeram crimes e, portanto, devem ser penalizadas de alguma forma:

...apesar de serem considerados assim, delinqüentes, mas são chamados de pacientes, ainda em tese, coisa e tal...na verdade, você não pode punir...tem que ver que são doentes mentais, não pode, mas tem que ver que...pôxa, mataram, estupraram... E1

...são humanos, mas que cometeram erros e têm que pagar por isso... E3

...por enquanto, o que eu acho...são muito imprevisíveis...a qualquer momento podem surpreender... E8

Problemas de ordem política são, muitas vezes, apontados nas falas dos agentes, geralmente de forma velada, das quais se pode inferir que o HCTP de Sergipe, como também é realidade em muitas outras organizações do tipo e em presídios do País, recolhe, com encaminhamento político ou de autorização judiciária, alguns presos de outras unidades como medidas de atenuação da pena e concessão de privilégios:

Têm pessoas que realmente necessitam de cuidados especiais e têm pessoas que eu acho que não deveriam estar aqui...de doido não têm nada... E2

...e muitos internos aqui não são realmente doentes mentais. E4

São pessoas doentes, nem todos...por determinação da Justiça, mandam pra cá e ficam aí. E9

Os pacientes são vistos como pessoas que são mantidas ociosas e pouco aproveitadas, não obstante haver doentes com as ditas inabilidades e incapacidades: 
...que os internos possam...se bem que alguns não podem desempenhar...não têm certas habilidades, coordenação, coisa e tal... e outros poderiam, entendeu? E1

...primeiro porque tem uns que são doentes mesmo, vamos dizer assim, que não têm habilidades pra fazer alguma coisa, mas já têm uns que já sabem ler, sabem escrever e poderiam aproveitar isso...mas, isso não tem. E3

Cumpre-nos salientar que o universo bem diferenciado dos entrevistados, a exemplo de variáveis que levam em conta a formação escolar e o tempo de instituição, contribui para que visões mais críticas insurjam e coloquem em discussão conceitos de normalidade $x$ anormalidade, loucura $x$ lucidez, punição $x$ tratamento:

\section{O papel do guarda prisional}

O guarda prisional do HCTP de Sergipe acredita que as suas atribuições continuam sendo as mesmas, quais sejam, as de vigiar, evitar fugas e manter a ordem; porém, alguns se sentem impelidos a "assumir" outros papéis e a preencher as lacunas institucionais devido ao fato de conviverem com pessoas em tratamento, além de se depararem continuamente com o Estado e a saúde que está em falta com o atendimento às demandas locais:

...o que vai pesar é: 'fugiu ou não fugiu no seu plantão?'...é isso que o sistema pede, que não deixe fugir...minha função continua sendo a mesma, não deixar fugir e mostrar o poder do Estado... E10

...eu estou aqui pra proteger e tomar conta dos internos, independente de ser doido ou não. E2

...a minha função aqui é somente guardar, entendeu? Cuidar da segurança física, entendeu? E, e preservar o ambiente aqui, entendeu? Não deixar que ocorra fuga...essa é a função do guarda prisional...mas, eu acho, essa é a função que está no papel. Mas eu acho que a função de guarda prisional vai além disso...ele é meio pai, meio mãe, meio advogado, meio psicólogo, meio assistente social... E6

...tem que procurar orientar mais, né? Tentar ajudar de uma forma ou de outra, né? Dá até uma de assistente social ou psicólogo, né? E5

...evitar fugas, evitar brigas deles...a atividade é essa aqui. E9

...o nosso papel é o mesmo: o nosso papel é a segurança...tomar conta, não deixar fugir...só que você acaba se envolvendo com a pessoa, conhecendo, participando dos problemas, dando opiniões na vida... E3

Os corretivos atrelados às atividades dos entrevistados foram freqüentemente pontuados como uma prática habitual e muito disseminada no HCTP, que, hoje, se não completamente extinta, foi bastante enfraquecida em razão das mudanças de concepção sobre o hospital, o interno e a saúde na instituição:

...quando eu cheguei, você ainda via alguma coisa relacionada a... tipo corretivo para o preso...que obedecesse alguma norma estabelecida pelo plantão, e realmente isso não se pratica, foi extinto isso, esse tipo de punição...E1

...mudou o comportamento...eu não lembro da última vez que teve algum espancamento. E3

No entanto, algumas práticas de controle são mantidas, em virtude mesmo da dinâmica do hospital, de seu regimento e das normas instituídas:

...mudou em alguns colegas que eu acompanhei...qualquer coisa era isolamento, né? Às vezes, tinha agressão a algum interno, né? Agressão física, né?....agora não é agressão física, é agressão psicológica...olha, você vai ..o nosso papel é o mesmo: o nosso papel é a segurança...tomar conta, não deixar fugir...só que você acaba se envolvendo com a pessoa, conhecendo, participando dos problemas, dando opiniões na vida... E3 
pro almoço tal hora, você vai dormir tal hora...são agressões, mas são mais veladas...isso mudou um pouco mais... E10

As atividades ainda são tidas como de risco, em conformidade com o estigma do louco infrator:

...sei, de repente, da reação de cada um, se pode me agredir, e tal...isso a gente tá exposto a qualquer hora... E2

Ao abordarem as relações entre a saúde e a Justiça no HCTP, ou seja, a interação entre os guardas prisionais e a equipe técnica, eles demonstram ser aquela ainda muito pouco imbricada, distante, onde cada qual cumpre o seu papel, e, no máximo, a aproximação está condicionada à segurança e à vigilância dos pacientes durante uma atividade terapêutica:

... a gente só faz a segurança porque... queira ou não, eles cometeram algum delito, e a gente faz parte da Justiça, mas a saúde...a gente só faz a custódia...quem faz o tratamento é a saúde...cada um faz o seu trabalho...vai tomar medicação, a gente acompanha, pra ver se não vai ter alguma confusão, quando tem alguma coisa, a gente tira...leva para o posto de saúde, a gente ajuda na parte da segurança. E3

...a saúde faz a dela, e a nossa é segurança. E9

...acho que o papel da enfermagem, o guarda acompanhando para guardar, por conta de um eventual incidente...sei lá..cortar as unhas, cortar cabelo, cuidar da limpeza... E6

.... g gente tem que trabalhar de comum acordo...eu sei o meu papel, você sabe, você é enfermeira, você sabe o seu...é um casamento harmonioso, digamos assim...eu acho que o hospital precisa do guarda prisional pra guardar. E6

Enquanto alguns revelam as dificuldades de desempenho de seu papel ou sequer vislumbram a possibilidade de ampliar os limites da atuação, temos falas que nos reportam à necessidade de firmar um compromisso ético e político em quaisquer atividades e de tentar ultrapassar os entraves burocráticos, os ditames institucionais e políticos através de modos de pensar mais críticos, notadamente quando do agenciamento de vidas humanas:

...eu acho que o meu papel muda a partir da minha vontade, a partir da minha vontade...aí você faz um pouquinho, aí tem outro que faz um pouquinho, aí a gente muda, a gente muda a cara disso aqui, entendeu? ...isso não é apenas um presídio que você sabe que o cara tá lá dentro, é a corrida do gato e do rato...a gente querendo, é impedir que ele fuja e ele querendo fugir...o papel do guarda prisional aqui é muito mais sério...e eu tenho perspectivas de também evoluir no meu papel...mas, se o Estado não criar condições, eu crio...não espero, eu crio condições... E6

...no conversar mais com o interno, tentar escutar o que eles estão falando, tentar, né? Porque antes nem isso...é louco, né?...um pouco essa mudança. Eu vejo mais em relação aos agentes do que à equipe técnica. Os agentes incorporaram mais um pouco...essa mudança de manicômio pra uma coisa mais, mais terapêutica, né?...mas, a equipe técnica...raras vezes chega um técnico...e eles são teoricamente capacitados pra aquilo...e raramente eles vão lá, entendeu?...pra conter é com a gente...quem tá lá no dia a dia somos nós...tá em crise...primeiros socorros mesmo...e nós não somos capacitados pra isso. Apesar de eu ter um olhar diferenciado...e eu aprendi muito mais com eles do que numa academia ou com o corpo técnico daqui... E10

\section{Saúde, aonde vai?!}

A entrada de profissionais de saúde na instituição, que gerou a expectativa de reorientação do modelo do HCTP de Sergipe, não foi sentida pelos guardas prisionais como a principal incitadora de mudanças no plano institucional, muito embora eles indiquem 
algumas. São modificações que, na sua ótica, ainda estão aquém das expectativas de transformação do HCTP em uma instituição hospitalar, pois, além das dificuldades materiais, as relações entre saúde e pacientes se dão muito superficialmente:

...mudou, mudou a estrutura, teve uma reforma....mudou, assim, remédio...é difícil faltar remédio pra eles, tem atividades de passeio, de levar à praia, aniversário do mês, que, queira ou não queria, é pouco, mas já ajuda, entendeu? E3

...se é hospital, precisa de médico, não tem médico, é...no caso de uma emergência, é a gente tem que ligar pro CDA pra vir uma viatura...e deveria ter uma ambulância aqui... E9

...mas, assim na parte dos internos, melhorou assim, o modo como eles vivem, a alimentação, o convívio, estão dando mais atenção ao problema deles. E7

...a única coisa que eu vi mudar foram os enfermeiros...mudança de pessoal. E4

Na sua compreensão, as ações de saúde se restringem à prescrição de medicamentos, sendo a atenção realizada de forma precária. É interessante notar que, embora afirmem não ser da área e desconhecer o campo de atuação, eles têm uma representação do que seja a saúde mental, a qual, segundo os entrevistados implícita e explicitamente assinalam, não se parece com a saúde mental que eles presenciam no ambiente:

...veja bem...eu não sei lhe dizer, por que eu não entendo da área, o que se trata realmente de um tratamento psiquiátrico, mas eu sei lhe dizer que medicados eles são...agora se deveria haver algum outro tipo de tratamento, se deveria, esse tratamento...não existe não... E4

...mas, o que eu vejo é o pessoal dando o remédio certinho. Todo dia o pessoal vem, passa o remédio pra ele. É como eu digo, não acho que é o suficiente, só remédio, remédio...mas, um acompanhamento mais de perto. E5

...mas eles tinham que ter sim, um acompanhamento...aqui é tudo um faz-deconta...aqui tem um psicólogo que não serve pra nada..aí eu não quero nem pensar, porque cada um na sua função...aqui tem um psicopedagogo que também não faz nada, tem um terapeuta que não faz nada...a enfermagem dá o remédio na hora certa...e também muitas vezes que nem se certifica que o interno realmente tomou, porque tem interno que cospe fora...tem interno que guarda, acumula, aí fica juntando, juntando..aí toma tudo de uma vez, entendeu?...é muito sério isso aqui. Isso aqui é tão sério, tão sério, é tão sério quanto a nossa casa... E6

é muito difícil também esse acompanhamento continuado...é mais pra apagar incêndio, aí vem com todas aquelas, aquelas medicações... E10

A imagem ideal que os entrevistados têm da saúde mental no HCTP de Sergipe é de um acompanhamento sistemático por parte dos profissionais, que exige responsabilidade e compromisso com a questão, "disposição" essa, que, por vezes, finda face aos encalços impostos pelo sistema, pela falta de assistência do Estado em relação aos seus agentes públicos e aos que estão sendo custodiados.

...aqui é de extrema...é de fundamental importância o profissional de saúde. Por que? Porque eles são pessoas que precisam, que têm uma patologia... eles não precisam de um guarda prisional, eles precisam de um acompanhamento médico...porque qual é a minha função? Não é guardar o preso? ...então quer dizer que o Estado joga um monte de homens como aqui tem, joga pra lá só pra eu guardar? E aí, o atendimento? E o acompanhamento? E essa responsabilidade que o Estado tem em acompanhar um tratamento psicológico de, de qualidade? Um tratamento médico de qualidade? Um tratamento é, 
odontológico de qualidade? É...um acompanhamento das famílias também? ...você também tem que preparar essa família que vai receber o interno como esse...então cadê a assistente social?E6

...eu não sei dizer como era antes sem a equipe técnica e com a equipe técnica...eu sei que, com ela...é.... gente tem todas as dificuldades de...qualquer coisa tem inúmeras burocracias, mas o problema é que as pessoas acabam se aprisionando por isso, né?...e não perceberam que, que aquilo que a gente aprendeu na universidade, tá aprendendo na universidade, não cabe nessa instituição...talvez, só quero ouvir, quero olhar, quero conversar, tal...não tem...quando tem é porque foi a pedido da Justiça...olha, o laudo... E10

...o que eu estou vendo é que os profissionais de saúde estão indo embora...não estão ficando não...tá todo mundo querendo sair. E4

A abertura do HCTP, verificada com a aproximação da Vara de Execuções Penais e do Ministério Público no que diz respeito ao processo de desinternação e reformas do prédio, na concepção dos entrevistados, não foi fruto de investimentos profissionais e pessoais da equipe de saúde, apesar de acreditarmos que a presença da saúde, de algum modo, contribuiu para esse movimento: ...felizmente teve uma mudança também na Vara de Execuções... é um pouco mais aberto...os funcionários lá conseguem uma articulação com ele e com os funcionários aqui...mas, eles que vieram, não os funcionários daqui... E10

...eu acho que alguém, o Ministério Público, é alguém de muito, lá de cima...resolveu interceder por eles...eu vejo pessoas aqui que convivem com eles há vinte anos e nunca fizeram nada pra mudar...nem a si próprio, nem o ambiente de trabalho e nem os internos, entendeu? Então eu acho que foi alguém de fora...o Ministério Público, é..sei lá, a Secretaria de Saúde que tem que intervir nisso. Acho que a área de saúde tá mais propícia a isso, entendeu? Porque não tem outra área, segurança pública não ia fazer isso, né verdade? A Justiça não ia fazer isso... E6

\section{Considerações finais}

O retorno ao Hospital de Custódia e Tratamento Psiquiátrico de Sergipe em momento bem distinto, abordando agora o grupo de guardas prisionais, foi de imensa valia, pois descobrimos que as representações sociais, diante do estranho, definido aqui como a saúde mental, estão sendo novamente elaboradas, ou seja, a instituição está longe de ser um hospital, não tem funcionalidade enquanto tal, dado o modelo de aprisionamento do sujeito, mas os entrevistados expressam a necessidade de fazer valer o projeto de reorientação proposto inicialmente com a entrada de profissionais de saúde.

Talvez a saída dos profissionais, bem como os problemas relacionados ao seu não engajamento, esteja, de algum modo, contribuindo para fazer emergir essa percepção com mais força, mas, certamente, a entrada foi o início da formação dessa representação.

A representação sobre o papel do guarda prisional orientou em muito pouco as práticas, pois continuam exercendo a mesma função instituída pelo Estado e pela sociedade, com plena noção da incumbência que Ihes foi designada, porém constatamos a dispersão de práticas punitivas e a progressiva sensibilização dos guardas à condição dos internos, que ainda são representados como inábeis e perigosos, em função de supostas reações imprevisíveis e surtos de agressividade.

Realmente, estamos longe de denominá-los pacientes, clientes ou usuários, contudo, torcemos para que tanto a situação jurídica quanto o acesso aos serviços de saúde sejam uma preocupação constante dos atores envolvidos e da política de atenção ao "louco infrator" no País. 
ABRIC, J.C. A Abordagem Estrutural das Representações Sociais. In: Moreira, A.S.P.; Oliveira, D. C. (orgs). Estudos Interdisciplinares de Representação Social. Goiânia: Ed. AB, 2000, pp.27 - 38.

AMARANTE, P.; TORRE, E. H. G. Protagonismo e Subjetividade: a Construção Coletiva no Campo da Saúde Mental. Ciência e Saúde Coletiva, v. 6, n.1, pp. 73-85, 2001.

CARRARA, S. Crime e Loucura. O Aparecimento do Manicômio Judiciário na Passagem do Século. Coleção Saúde e Sociedade, Rio de Janeiro, EdUERJ/EdUSP, 1998.

DANTAS, M. A. F. Interfaces entre Saúde e Justiça: Expectativas de Reorientação da Política de Atenção ao Louco Infrator no Manicômio Judiciário de Sergipe. Monografia de Especialização em Psicologia social. Universidade Estadual de Santa Cruz, Ilhéus/BA, 2003.

FOUCAULT, M. (org.) Eu, Pierre Rivière, que Degolei minha Mãe, minha Irmã e meu Irmão. Trad. Denize Lezan de Almeida. $6^{a}$ ed. Rio de Janeiro: Graal. 2000a.

FOUCAULT, M. Doença Mental e Psicologia. 6 a ed. Rio de Janeiro: Tempo Brasileiro, 2000b.

Vigiar e Punir. Nascimento da Prisão. Trad. Raquel Ramalhete. 24르. ed. Petrópolis: Editora Vozes, 2001

GOFFMAN, E. Manicômios, Prisões e Conventos. Trad. Dante Moreira Leite. 7a ed. São Paulo: Editora Perspectiva, 2001.

GOMES, L. F. (org.) Código Penal. São Paulo: Editora Revista dos Tribunais, 2004

KINOSHITA, R. T. Contratualidade e Reabilitação Psicossocial. In: Pitta, A. (org.) Reabilitação Psicossocial no Brasil. São Paulo: Editora Hucitec, 1996, pp. 55-62.

MACIEL, L. R. A Loucura Encarcerada: um Estudo sobre a Criação do Manicômio Judiciário do Rio de Janeiro (1896-1927). Dissertação de Mestrado em História Universidade Federal Fluminense, Rio de Janeiro, 1999.
MINISTÉRIO DA SAÚDE. Portaria Interministerial no $\mathbf{6 2 8}, 02$ abril de 2002.

MOSCOVICl, S. Das Representações Coletivas às Representações Sociais: Elementos para uma História. In: Jodelet, D. (org.) As Representações Sociais. Trad. Lílian Ulup.Rio de Janeiro: EDUERJ 2001, pp. 45-66.

NÓBREGA, S. M. da. Sobre a Teoria das Representações Sociais. In: Moreira, A. S. P. (org). Representaçóes Sociais: Teoria e Prática João Pessoa: Ed. Universitária/Autor Associado, 2001, pp. 55-87.

PERES, M. F. T. Doença e Delito: Relação entre Prática Psiquiátrica Judiciária e Poder Judiciário no Hospital de Custódia e Tratamento de Salvador, Bahia. Dissertação de Mestrado em Saúde Comunitária. Universidade Federal da Bahia, 1997.

PERES, M. F. T.; NERY FILHO, A. A Doença Mental no Direito Pena Brasileiro: Inimputabilidade, Irresponsabilidade, Periculosidade e Medida de Segurança. História, Ciências, Saúde, Manguinhos, Rio de Janeiro, v. 9, n. 2, pp. 335-355, 2002.

RIBEIRO, P. R. M. Saúde Mental no Brasil. São Paulo: Arte e Ciência, 1999.

ROTELLI, F.; DE LEONARDIS, O.; MAURI, D. Desinstitucionalização, uma outra Via. In: Nicácio, F. (org.) A Reforma Psiquiátrica Italiana no Contexto da Europa Ocidental e dos "Países Avançados". São Paulo: Ed. Hucitec, 1990, pp. 17-59.

WAGNER, W. Descrição, Explicação e Método na Pesquisa das Representações Sociais. In: Guareschi, P.; Jovchelovitch, S. (orgs.) Textos em Representações Sociais. Petrópolis: Vozes, 1994, pp. 149-183.

WAGNER, W. Sócio-gênese e Características das Representações Sociais. In: Moreira, A.S.P.; Oliveira, D. C. (orgs). Estudos Interdisciplinares de Representação Social. Goiânia: Ed. AB, 2000, pp.03- 25 . 